\title{
DERECHO A UN ENTORNO URBANO DE CALIDAD
}

Right to a quality urban environment

DOI: http://dx.doi.org/10.15304/dereito.29.Ext.6575

Mauricio Ruiz Ceniceros

Profesor asociado y abogado

Universidad de Vigo (España)

ORCID ID: https://orcid.org/0000-0002-6142-2587

maruiz@uvigo.es

\section{RESUMEN}

Para que una vivienda sea digna y adecuada debe reunir una calidad interior y condiciones extrínsecas sin las cuales no será apta ni decorosa. Difícilmente una vivienda, por muy lujosa que sea, podrá reunir las condiciones óptimas de habitabilidad si se encuentra en un ámbito cuya ejecución urbanística no ha sido totalmente rematada, o en un entorno urbano degradado, con unas dotaciones, servicios e infraestructuras en proceso de ruina. A pesar de lo cual la legislación reguladora del derecho de vivienda se ha centrado en garantizar el primer aspecto, pero ha descuidado el segundo. El objeto del presente artículo es poner de manifiesto esa laguna normativa y la conveniencia de adoptar medidas legislativas que doten a la ciudadanía de acción contra la Administración para exigir el cumplimiento de unas condiciones urbanísticas sin las cuales el derecho a una vivienda digna y adecuada no puede ser efectivo.

Palabras clave: vivienda digna y adecuada, regeneración y renovación urbana, inactividad administrativa.

\begin{abstract}
In order for a dwelling to be decent and adequate, it must be a inner quality and external conditions without which it will not be fit to live in a suitable or decent way. However luxurious a house is, it will hardly meet conditions to be fit to live in if it is in an area with unfinished urban development, or in a degraded urban environment, with some endowments, services and infrastructure half way to wreck. Laws regulating the right of housing has focused on guaranteeing the first aspect, but has neglected the second. The purpose of this article is to highlight this regulatory gap and the convenience of passing laws which provide citizens with action against the Administration to demand compliance with urban planning conditions without which the right to decent and adequate housing cannot be effective.
\end{abstract}

Keywords: dwelling decent and adequate, urban regeneration and renovation, administrative stagnation,

\section{SUMARIO}

1. ASPECTOS INTRODUCTORIOS.- 2. VIVIENDA DIGNA Y ADECUADA.- 2.1. Habitabilidad del recinto interno destinado a hogar. 2.2. Calidad del hábi- 
tat.- 3. DÉFICIT REGULARIO DE LA REGENERACIÓN Y RENOVACIÓN URBANA DESDE EL PUNTO DE VISTA DEL DERECHO A LA VIVIENDA.- 4. REGENERACIÓN Y RENOVACIÓN URBANA COMO OBLIGACIÓN ADMINISTRATIVA: UN INTENTO FALLIDO.- 5. ACCIÓN PARA EXIGIR LA REGENERACIÓN Y RENOVACIÓN URBANA DE INFRAESTRUCTURAS, EQUIPAMIENTOS, SERVICIOS Y ESPACIOS PÚBLICOS.- 6. CONCLUSIONES.- 7. BIBLIOGRAFÍA.

\section{ASPECTOS INTRODUCTORIOS}

Cuando se aborda la configuración, contenido y alcance del derecho a la vivienda lo primero que llama la atención es su importancia histórica, social y económica, en contraste con la imprecisión de su formulación jurídica, hasta el punto poner en duda que realmente sea un derecho. La Constitución lo recoge en el Capítulo Tercero del Título I entre los "Principios Rectores de la política social y económica", con la apariencia de otro mandato más de política legislativa y de actuaciones administrativas, sin categoría de derecho subjetivo ${ }^{1}$. Por fortuna, la interpretación que prevalece es que en el Capítulo Tercero existen tres preceptos donde se observa el reconocimiento expreso de derechos: la protección de la salud en el artículo 43; el disfrute del medio ambiente en el artículo 45, y el disfrute de una vivienda en el artículo 47. Estas excepciones no pueden ser casuales, sino la voluntad indubitada de otorgarles el rango de derechos constitucionales ${ }^{2}$; e implica que la actuación de los poderes públicos, la legislación, así como las decisiones judiciales han de garantizar el respeto y la protección de estos derechos (art. 53.3 de la Constitución)3. Pero sin llegar a otorgarles el valor de derechos fundamentales ${ }^{4}$, porque no han sido incluidos en el lugar propio de estos últimos (Capítulo Segundo del Título I), aunque algunas leyes autonómicas digan lo contrario ${ }^{5}$. Tampoco les confiere mayor jerarquía su consagración en los Estatutos de Autonomía6.

\footnotetext{
${ }^{1}$ E. RODRÍGUEZ ACHÚTEGUI, E., "Derecho a la vivienda: de principio rector a derecho subjetivo", en Revista Aranzadi Doctrina, número 8, 2015, p. 14.

2 J. MÚNNOZ CASTELLO, Constitución y vivienda, Centro de Estudios Políticos y Constitucionales, Madrid, 2003, pp. 17 y 18. Por ejemplo, éste es el rango que le atribuye el Preámbulo de la Ley 8/2012, de 29 de junio, de vivienda de Galicia.

${ }^{3}$ E.R. BARTLETT CASTELLA, "El derecho de acceso a la vivienda", en Cuadernos de Cristianisme i Justícia, no 144, diciembre 2006, p. 6.

${ }^{4} \mathrm{~A}$ pesar de otra posible interpretación sistemática, porque: «Si se atiende a la literalidad de los preceptos, podría entenderse que todos aquellos derechos situados bajo el Título De los Derechos y Deberes fundamentales son derechos fundamentales [...]» (A. BALAGUER PÉREZ, El Derecho a la Vivienda en el Derecho Constitucional Europeo, Editorial Aranzadi, Cizur Menor, marzo 2018, p. 103). ${ }^{5}$ Por ejemplo, la Ley 2/2017, de 17 de febrero, de emergencia social de la vivienda de Extremadura; la Ley 4/2016, de 23 de diciembre, de medidas de protección del derecho a la vivienda de las personas en riesgo de exclusión residencial de Cataluña; y la Ley 8/2004, de 20 de octubre, de la Generalitat, de la Vivienda de la Comunidad Valenciana, argumentando que los tratados internacionales que reconocen la vivienda como derecho fundamental forman parte del ordenamiento interno español (artículo 93.1 Constitución). Opina lo contrario J.M. SOUVIRÓN MORENILLA, "El derecho a la vivienda y su garantía pública: entre el servicio público y la protección social", en Servicios de interés general y protección de los usuarios: (educación, sanidad, servicios sociales, vivienda, energía, transportes y comunicaciones electrónicas) (Dir. I. González Ríos), Editorial Dikinson, S.L., Madrid, 2018, p. 182, porque el art. 10.2 restringe los derechos fundamentales que se deben interpretar a la luz de los Tratados Internacionales. Por eso la Exposición de Motivos de la Ley Foral 28/2018, de 26 de diciembre, sobre el derecho subjetivo a la vivienda en Navarra sigue asumiendo que la vivienda que no está reconocida como derecho fundamental, ni tiene las garantías procesales y sustantivas que merece.

${ }^{6}$ El artículo 25 de la Ley Orgánica 2/2007, de 19 de marzo, de reforma del Estatuto de Autonomía para Andalucía; los artículos 14 y 22 de la Ley Orgánica 1/2018, de 5 de noviembre, de reforma del Estatuto de Autonomía de Canarias; el artículo 26 de la Ley Orgánica 6/2006, de 19 de julio, de reforma del Estatuto de Autonomía de Cataluña; y artículo 16 de la Ley Orgánica 1/2006, de 10 de abril, de reforma
} 
La principal consecuencia es que el alcance, contenido y vías jurisdiccionales para la defensa del derecho a la vivienda no derivan directamente de la Constitución, sino que dependerá de lo que establezca la legislación que lo desarrolle (artículo 53.3 Constitución) ${ }^{7}$. Es decir, no configura un derecho subjetivo constitucional al acceso y disfrute de una vivienda ${ }^{8}$, sino «el derecho a que se establezcan derechos» que sí podrán ser verdaderos derechos subjetivos dependiendo de la legislación que los regule9.

La segunda consecuencia es que no cuenta con los mecanismos de tutela jurisdiccional reforzada ni la reserva de ley orgánica previstas en los artículos 53, apartados 1 y 2, y 81 de la Constitución. Su cumplimiento o incumplimiento sólo puede ser fiscalizado por la jurisdicción ordinaria a través de los trámites procesales ordinarios ${ }^{10}$. Motivo por el cual se objeta que la Constitución presenta el derecho a la vivienda con escaso peso jurídico, adoleciendo de debilidad normativa y contando con poca protección jurisdiccional ${ }^{11}$.

Por último, desde el punto de vista constitucional la vivienda es una materia de competencia autonómica ${ }^{12}$, pero en la que el Estado -al amparo de su competencia exclusiva para la fijación de las «bases y coordinación de la planificación general de la actividad económica» (artículo 149.1.13 Constitución)- puede adoptar medidas con el fin de hacer frente a las necesidades sociales en el ámbito de la vivienda. Es uno de los ejemplos más característicos de las denominadas competencias «horizontales» o «transversales», es decir los « títulos competenciales transversales de titularidad estatal que

del Estatuto de Autonomía de la Comunidad Valenciana reconocen el «derecho fundamental» de acceso a la vivienda. Pero lo cierto es que esta proclamación estatutaria no lo convierte en derecho fundamental en sentido estricto derecho; únicamente son principios o mandatos hechos por cada Estatuto a los poderes públicos de la correspondiente Comunidad Autónoma, de modo que sólo mediante su desarrollo legislativo adquirirán la condición de auténticos derechos subjetivos (STC 247/2007, Pleno, de 12 de diciembre7, Rec. 7288/2006, FJ. 200; STC 249/2007, Pleno, de 13 diciembre, Rec. 7289/2006, FJ 50; y STC 31/2010, Pleno, de 28 de junio de 2010, Rec. 8045/2006, FJ. 16).

7 J.M. SOUVIRÓN MORENILLA, "El derecho a la vivienda y su garantía pública... op. cit, p. 182.

8 La doctrina constitucional mayoritaria considera que los principios rectores contenidos en el Capítulo III del Título I de la Constitución no otorgan derechos subjetivos, generando una profunda insatisfacción porque: «si el legislador no se esfuerza en caracterizar las declaraciones que dispuso el constituyente, quedan proclamadas, pero inefectivas. Habrá de haber política de vivienda, porque así lo dispone la norma fundamental, pero no un derecho subjetivo a exigir un determinado proceder» (E. RODRÍGUEZ ACHÚTEGUI, "Derecho a la vivienda: de principio rector a derecho subjetivo... op. cit. p.14). PONCE SOLÉ disiente y considera que el derecho a la vivienda previsto en la Constitución española, como otros derechos sociales, es un auténtico derecho subjetivo que genera obligaciones de medios, no de resultados (J. PONCE SOLÉ, "La tutela judicial del derecho a la vivienda y el papel del Tribunal Constitucional español: luces y sombras en el contexto europeo e internacional", en Derecho a la vivienda y función social de la propiedad [Coords. J.P. Moltó Darner y J. Ponce Solé], Editorial Aranzadi, Cizur Menor, 2017, p. 65)

${ }^{9}$ Así lo explica la Exposición de Motivos de la Ley 2/2007, de 1 de marzo, de Vivienda de la Comunidad Autónoma de La Rioja, aunque plantea dudas y problemas tanto a los poderes públicos como a los operadores jurídicos porque: «¿La eficacia de este derecho expresamente reconocido es exactamente igual que la de los "Principios rectores" que no tienen tal determinación?, o, ¿es posible predicar un mayor grado de eficacia a los "Principios Rectores" que explícitamente señalan "derechos", y, si fuera así, ¿Cuál puede ser ese mayor grado de eficacia?» (J. MúÑ̃Z CASTELLO, Constitución y vivienda... op. cit. p. 18).

$10 \mathrm{Ni}$ siquiera quienes sostienen que la categoría «Derechos fundamentales» es unitaria para todos aquellos reconocidos en el Título Primero de la Constitución, niegan que las técnicas de protección y garantías procesales varían de unos a otros (. HERRANZ CASTILLO, "Consideraciones sobre el derecho a la vivienda en la Constitución... op. cit, pp. 5 y 6 ).

11 M. DE LA CABEZA MENA ESTRELLA, "Critica jurídica al artículo 47 de la Constitución española: el derecho a una vivienda digna como referente de la calidad democrática", en Revista de Estudios jurídicos número 17, 2017 (Segunda Época), versión electrónica: rej.ujan.es (5/03/2020), p. 4.

12 Artículo 148.1.3a de la Constitución española. 
tienen incidencia en materias como "vivienda" que el bloque de la constitucionalidad ha reservado a la exclusiva competencia autonómica»13. Además es un derecho «medial», porque está conectado con otros derechos sociales y civiles clásicos que dependen de él para ser efectivos, y con otros derechos de carácter económico que le sirven de límite ${ }^{14}$.

En todo caso, lo importante es que el derecho a la vivienda responde a la categoría de derecho socia/15, esto es un «derecho de igualdad» que tiene como punto de partida una situación social e histórica desigualitaria e insatisfactoria, y como punto de llegada u objetivo final la cobertura de una necesidad básica. En concreto, el artículo 47 de la Constitución va dirigido a quienes no poseen una vivienda digna, o tienen importantes dificultades para conseguirla. «No es un derecho para todos, sino que es un derecho para los sectores concretos de la población que lo necesitan realmente»16. Desde este punto de vista, es un derecho de segunda generación, de acción positiva o de prestación, y de protección ${ }^{17}$.

El problema es que, en realidad, su protección queda a cargo del legítimo juego de las mayorías democráticas sin ningún límite superior y con un peligro evidente: que prácticamente cualquier regulación en la materia pueda ser considerada conforme a la directriz fijada en el artículo 47 de la Constitución ${ }^{18}$. El Tribunal Constitucional ha declarado que, en atención a este precepto, toda política de vivienda debe tener señalado acento social, porque constituye un mandato o directriz constitucional que ha de informar la actuación de todos los poderes públicos ${ }^{19}$. Pero dentro de este amplísimo margen caben, por ejemplo, tanto una legislación que liberalice al máximo la urbanización del territorio, como aquella que prioriza el uso racional del suelo, invocando ambas la efectividad del derecho a la vivienda ${ }^{20}$.

En realidad todas estas cuestiones no son nuevas porque en España el problema de la vivienda es histórico y endémico ${ }^{21}$. Tanto en tiempos de bonanza

\footnotetext{
${ }^{13}$ Al respecto véase M.A. ÁRIAS MARTÍNEZ, "Las competencias autonómicas en materia de vivienda frente a las competencias estatales de carácter transversal en la reciente jurisprudencia constitucional", en REALA. Nueva Época, número 11, Abril-Septiembre 2019, p. 120.

${ }^{14}$ Sin salir del propio texto constitucional, el principio del Estado social de Derecho (artículo 1.1), la dignidad de la persona (artículo 10.1), el principio de igualdad formas (artículo 14) y material (artículo 9.2), el derecho a la integridad física y moral (artículo 15), a la intimidad (artículo 18), la libertad de residencia (artículo 19), el derecho a la educación (artículo 27), el derecho a la salud (artículo 45), el derecho de propiedad (artículo 33) y el de iniciativa privada (artículo 38). En este sentido, véase DE LA CABEZA MENA ESTRELLA, M., "Critica jurídica al artículo 47 de la Constitución española... op. cit., p. 5. ${ }^{15}$ Por ejemplo, en la Exposición de Motivos de la Ley 5/2018, de 19 de junio, de la vivienda de las Islas Baleares; de la Ley $11 / 2019$, de 11 de abril, de promoción y acceso a la vivienda de Extremadura; y de la Ley 1/2010, de 8 de marzo, Reguladora del Derecho a la Vivienda en Andalucía.

${ }^{16}$ R. HERRANZ CASTILLO, "Consideraciones sobre el derecho a la vivienda en la Constitución", en Diario La Ley, número 5823, Sección Doctrina, 15 de julio de 2003, https://laleydigital-laleynext-es.biblioteca (05/03/2020), p. 3.

17 Sobre la distinción entre derechos de primera y segunda generación; derechos de acción negativa o de defensa tradicionales frente a derechos de acción positiva o de prestación; y derechos a protección vs. derechos de defensa, véase A. BALAGUER PÉREZ, El Derecho a la Vivienda en el Derecho Constitucional Europeo..., op. cit. pp. 35-39.

${ }^{18}$ C. MONTESINOS PADILLA, "El derecho a la vivienda (o del porqué y del cómo reformar la Constitución en materia de derechos sociales)", en Revista Aranzadi Doctrinal, número 2, 2019, pp. 3 y 9.

${ }_{19}$ STC 152/1988, Pleno, de 20 de julio, Rec. 325/1987, FJ. $2^{\circ}$.

20 Por ejemplo, las derogadas Ley $6 / 1998$, de 13 de abril, sobre régimen del suelo y valoraciones, en un extremo, y la Ley $8 / 2007$, de 28 de mayo, de suelo, en el otro, pero ambas con un objetivo común: poner los medios para la efectividad del derecho a la vivienda.

${ }^{21}$ El Informe sobre el proyecto de ley de casas baratas presentado a la Comisión del Senado por Torres-Cabrera (Instituto de Reformas Sociales, 1907)I señalaba que tenía por finalidad «proporcionar a las familiar poco acomodadas, en el disfrute de sus domicilios, moralidad, higiene, seguridad, economía,
} 
y burbuja inmobiliaria, como cuando ésta estalla y sobreviene la crisis económica, existe un sector de la sociedad con serias dificultades de alojamiento que exige cuatro soluciones muy concretas: número de viviendas suficientes para cubrir las necesidades que surgen en la sociedad; adecuación de las características residenciales a las necesidades personales y familiares; precio asequible; y acondicionamiento material de las viviendas ${ }^{22}$. El presente artículo se centra en este último aspecto, la inadecuación e indignidad de la morada cuando se encuentra: «En una callejuela torcida y estrecha, desagradable y hedionda; cruzada por otras callejuelas torcidas y estrechas [...] Las descabalgadas piedras del pavimento, que formaban infinidad de pequeños hoyos de barro y agua, carecían de aceras y terminaban bruscamente en las mismas puertas de las casas. El arroyo, para compensar tales deficiencias, corría por el centro de la calle (cuando corría, que solía ser después de las grades lluvias, y entonces lo hacía, por infinidad de excéntricos escapes, hasta el interior de los edificios, metiéndose por las puertas). Muy de trecho en trecho colgaba de una cuerda y de una polea un tosco farol atravesado en lo alto de la calle $[\ldots]^{23}$ ».

\section{VIVIENDA DIGNA Y ADECUADA}

El contenido esencial del derecho a la vivienda ha evolucionado en función del alcance que se ha querido dar a su reconocimiento. La Declaración de derechos de Virginia y la Declaración de los derechos del hombre y del ciudadano ni siquiera lo mencionaron; la Declaración Universal de derechos humanos lo proclama como condición necesaria para alcanzar un nivel de vida adecuado ${ }^{24}$; la Convención Internacional sobre la eliminación de todas las formas de discriminación racial lo considera derecho esencial para garantizar el derecho a la igualdad25; y la versión originaria de la Carta Social Europea lo declara elemento de protección social, jurídica y económica a la que tiene derecho la familia26. Fue finalmente en el Pacto internacional de derechos económicos, sociales y culturales donde se exige que la vivienda sea adecuada ${ }^{27}$, requisito al que la Constitución española y la Carta de los Derechos fundamentales de la Unión Europea añaden que sea digna28.

comodidad, hábitos de cultura y medios para que lleguen a tener casa propia» (M.A. CASTRILLO ROMON, "Influencias europeas sobre la "Ley de Casas Baratas" de 1911: «Loi des Habitations à Bon Marché» de 1984, en Cuadernos de investigación urbanística, número 36, 2003, pp. 8).

22 Al respecto véase L. CORTÉS ALCALÁ, "El problema de la vivienda en España: elementos para su comprensión", en Política y Sociedad, número 10, 1992, Madrid, pp. 74 y 75.

${ }^{23}$ Charles DICKENS, de A tale of Two Cities , Libro Primero, Capítulo V "La taberna", 1859, edit. Diario EL PAIS, S.L., Madrid, 2004. p. 45.

${ }^{24}$ Artículo 25 de la Declaración Universal de Derechos Humanos, de 10 de diciembre de 1948

${ }^{25}$ Artículo 5.e.iii) de la Convención Internacional sobre la eliminación de todas las formas de discriminación racial, de 21 de diciembre de 1965.

${ }^{26}$ Artículo 16 de la Carta Social Europea de 18 de octubre de 1961.

27 Artículo 11.1 del Pacto Internacional de 19 de diciembre de 1966, sobre derechos económicos, sociales y culturales.

${ }^{28}$ Artículo 47 de la Constitución española de 6 de diciembre de 1978, que es una novedad en el marco del constitucionalismo europeo hasta la aparición de los textos promulgados en el sur de Europa durante la década de los setenta, salvo el artículo 155 de la Constitución de Weimar de 1918, (G.J. RUIZ-RICO RUIZ, El derecho constitucional a la vivienda. Un enfoque sustantivo y constitucional, Secretaría General Técnica, Centro de Publicaciones, del Ministerio de la Vivienda, Madrid, 2008, p. 7). El artículo 34.3 de la Carta de los Derechos Fundamentales de la Unión Europea, de 12 de diciembre de 2007, lo limita a quienes no dispongan de recursos suficientes, por influencia de los Estados miembros que frenan el desarrollo de los derechos sociales (C. MIALOT, "Diez años de la Ley DALO (derecho a la vivienda exigible) en Francia y el contexto europeo", en La Ley del derecho a la vivienda de Catalunya: diez años de vigencia. Balance y futuro (Coord. Observatorio desc Instituto de investigación Trans]uns), Thomson Reuters, Cizur menor (Navarra), 2018, p. 62. 
Pero el problema es determinar qué se entiende por vivienda digna y adecuada. La Constitución de Weimar se conformaba con que fuese una morada sana29; a la Constitución de México le basta que sea «digna y decorosa» 30 ; a la Constitución de Uruguay que sea «higiénica y económica»31; la Constitución de Nicaragua quiere que sea «digna, cómoda y segura que garantice la privacidad familiar»32; la Constitución de Portugal requiere que sea «una vivienda de dimensiones adecuadas, en condiciones de higiene y comodidad y preserve la intimidad personal y la privacidad familiar» 33 ; la Constitución de Venezuela exige que sea «adecuada, segura, cómoda, higiénica, con servicios básicos esenciales que incluyan un hábitat que humanice las relaciones familiares, vecinales y comunitarias»34; y la Constitución de Ecuador se conforma con «un hábitat seguro y saludable», y «una vivienda adecuada y digna» 35 . Mientras que en el ámbito normativo de la Unión Europea, «sin un alojamiento respetable y adaptado a las necesidades vitales de la persona no se podría dar cumplimiento al mandato»36. Es decir, los tratados de la Unión Europea y la Constitución española formulan unas adjetivaciones gramaticalmente claras, pero bastante difusas desde el punto de vista jurídico, sin proporcionar la definición concreta de lo que sea una vivienda digna y adecuada.

Con estos mimbres el método de interpretación de la dignidad y adecuación tiene que ser sistemático y «realista», buscando la conexión con otros preceptos para encontrar el significado que puede tener tal componente subjetivo en el ámbito específico de este derecho constitucional, porque si el listón de exigencias se fija demasiado alto se corre el riesgo de imponer un límite inasumible para la edificación ${ }^{37}$. Es decir, si resulta indigno que una persona «se vea en la necesidad de habitar hacinada como un animal en locales inmundos sin las más elementales condiciones sanitarias e higiénicas», el alcance de esa dignidad debe determinar un estándar mínimo de habitabilidad; que tiene que ser siempre garantizado por el poder público en las diferentes actuaciones encaminadas a hacer realidad ese derecho; y cuya concreción compete al derecho legislativo de la Unión Europea y a las legislaciones nacionales de los Estados atendiendo a dos parámetros ${ }^{38}$ :

\subsection{Habitabilidad del recinto interno destinado a hogar}

El cumplimiento de los requisitos de dignidad y adecuación implican unas condiciones mínimas de habitabilidad del espacio físico donde se desarrolla la vida personal y familiar. Por tanto, es un concepto que se refiere tácita-

\footnotetext{
${ }^{29}$ Artículo 155 de la Constitución de Weimar de 11 de agosto de 2019.

${ }^{30}$ Artículo 40 de la Constitución Política de los Estados Unidos de México, publicada en el Diario Oficial de la Federación el 5 de febrero de 1917, en párrafo adicionado y publicado el 7 de febrero de 1983.

${ }^{31}$ Artículo 45 de la Constitución de la República Oriental de Uruguay, que entró en vigor el 15 de febrero de 1967.

${ }^{32}$ Artículo 64 de la Constitución Política de Nicaragua, de 9 de enero de 1987.

${ }^{33}$ Artículo 65.1 de la Constitución de Portugal de 2 de abril de 1976.

${ }^{34}$ Artículo 82 de la Constitución de la República Bolivariana de Venezuela, de 15 de diciembre de 1999.

${ }^{35}$ Artículo 30 de la Constitución de Ecuador, de 22 de octubre de 2008.

${ }^{36}$ G.J. RUIZ-RICO RUIZ, El derecho constitucional a la vivienda... op. cit., p. 26.

37 J. GONZÁLEZ PÉREZ, El derecho a una vivienda digna en la Ley de Suelo de 2008, Colección Cuadernos de Derecho Registral, Edit. Fundación Registral, 2008, pp. 34-36.

${ }^{38}$ G.J. RUIZ-RICO RUIZ, El derecho constitucional a la vivienda... op. cit, pp. 25 y 29.
} 
mente a elementos «internos» de la vivienda, tales como la higiene, comodidad o la dimensión espacial ${ }^{39}$, con un diseño para todas las personas ${ }^{40}$.

En principio, corresponde a la legislación reguladora de la vivienda determinar las condiciones objetivas para «asegurar la calidad, mediante el cumplimiento de los requisitos básicos de la edificación y la adecuada protección de los intereses de los usuarios» ${ }^{41}$. Calidad que, en términos de vivienda, significa que -tanto si se trata de una casa como de un apartamento- el local debe presentar características adecuadas para responder a sus funciones, que dependen estrechamente de las evoluciones sociológicas y técnicas, así como del interés general que justifica la intervención administrativa y determina la aprobación de las normas las regulan. La vivienda siempre debe satisfacer reglas de funcionalidad, accesibilidad, seguridad y salubridad, definidas esencialmente en beneficio de sus ocupantes ${ }^{42}$, y que normativamente concretan la Ley 38/1999, de 5 de noviembre, de Ordenación de la Edificación; el Real Decreto 314/2006, de 17 de marzo, por el que se aprueba el Código Técnico de la Edificación, y la Orden de 29 de febrero de 1944, por la que se establecen las condiciones higiénicas mínimas de las viviendas ${ }^{43}$, ahora sustituida por la normativa autonómica ${ }^{44}$ y completada por la normativa urbanística.

Estas normas no sólo regulan las exigencias básicas de calidad de los edificios de nueva construcción y sus instalaciones, sino también las intervenciones que se realicen en los edificios existentes, porque tan importante como planificar, proyectar y ejecutar los edificios conforme a los requisitos básicos de funcionalidad, seguridad, habitabilidad y accesibilidad es conservarlos manteniendo e incorporando los elementos que determinan los niveles y parámetros mínimos exigibles de calidad ${ }^{45}$. Todo ello atendiendo al principio de discrecionalidad técnica que se proyecta sobre el carácter progresivo de la incorporación de las medidas arquitectónicas y tecnológicas, construcción de nuevos modelos adaptados a la variabilidad y diversi-

\footnotetext{
39 Ibid., p. 30.

${ }^{40}$ Artículo 5.a) del Real Decreto Legislativo 7/2015, de 30 de octubre, por el que se aprueba el texto refundido de la Ley de Suelo y Rehabilitación Urbana.

41 J. GONZÁLEZ PÉREZ, El derecho a una vivienda digna en la Ley de Suelo de 2008... op. cit., p. 29, que cita literalmente el artículo 1.1 de la Ley 38/1999, de 5 de noviembre, de Ordenación de la Edificación.

42 V. INSERGUET-BRISSET, "La evolución del Derecho francés en materia de vivienda", en Construyendo el derecho a la vivienda (Coord. F. López Ramón), Marcial Pons, Ediciones Jurídicas y Sociales, Madrid, 2010, pp. 50 y 51.

${ }^{43}$ Cuyo principal instrumento de control era la cédula de habitabilidad, que partió del Decreto de 4 de julio de 1938 que creó la Comisión de Control de Sanidad Local; la Orden de 25 de mayo de 1939 que creó el Servicio de Cédula de Habitabilidad; la Orden de 6 de febrero de 1939 que creó el Consejo Superior de Sanidad, en el que se integró el Fiscal Superior de Vivienda, y la Orden ministerial de 16 de septiembre de 1943 que reguló la Cédula de Habitabilidad; y que fue seguido por el Decreto 316/1960; la Orden ministerial de 30 de octubre de 1965; la Orden ministerial de 13 de noviembre de 1968; el Decreto 469/1972, de 24 de febrero, y el Decreto 129/1985, de 23 de enero (M.L. GÓMEZ JIMÉNEZ, La intervención administrativa de la vivienda en España 1938-2005, Montecorvo, Madrid, 2006, pp. 49 a 55).

${ }^{44}$ En ejecución de sus competencias en materia de vivienda han regulado de manera generalizada las autorizaciones administrativas que controlan que los inmuebles destinados a vivienda cumplan los requisitos de calidad y habitabilidad exigidos por el ordenamiento jurídico, así como las cédulas de habitabilidad, ya sea para mantenerlas o para suprimirlas (Andalucía, Castilla-La Mancha, Extremadura, Galicia, País Vasco y Comunidad Valenciana) (D. SIBINA TOMÁS, "La calidad del parque inmobiliario", en El derecho a la vivienda en el siglo XXI: sus relaciones con la ordenación del territorio y el urbanismo (Coords. J. Ponce Solé y D. Sibina Tmás), Marcial Pons, Madrid, 2007, p. 367).

${ }^{45}$ Artículo 3 de la Ley 1/2010, de 8 de marzo, Reguladora del Derecho a la Vivienda en Andalucía.
} 
dad de las unidades familiares, e innovación en la concepción y diseño, situando como único límite del deber legal de rehabilitar la declaración de ruina económica ${ }^{46}$.

\subsection{Calidad del hábitat}

Pero la vivienda digna y adecuada también necesita una habitabilidad "externa" o espacial apropiada y acondicionada, es decir que el hábitat que la rodea cuente con unas infraestructuras, servicios y equipamientos públicos con el mismo nivel de exigencia ${ }^{47}$, para lo cual debe ser accionado el resorte de la política de la ciudad «porque el barrio no debe ya solamente satisfacer las necesidades de la vivienda sino responder a las necesidades de equipamientos públicos, y de equipamientos comerciales y socio-culturales» ${ }^{48}$. Este requisito significa la imperiosa necesidad de contar con un «entorno ambiental» racional y sostenible. Sin la combinación de ambos presupuestos (habitabilidad interna y hábitat sostenible) la vivienda no puede ser ni digna ni adecuada ${ }^{49}$. Esta exigencia no es una mera proyección del derecho a disfrutar del medio ambiente adecuado en todas sus manifestaciones ${ }^{50}$, sino que vinculado al domicilio adquiere una entidad propia y autónoma, como requisito ineludible para que este sea digno y adecuado ${ }^{51}$, porque sin este otro nivel complementario no responderá a los términos de calidad. Es decir, el acondicionamiento interior de la vivienda es indispensable, pero no suficiente para que responda a sus funciones, porque se inscribe en un medio ambiente que es el barrio. «La cohesión social de la que la vivienda es un elemento determinante supone que ésta se inserta en un espacio que responde a las necesidades de los habitantes» ${ }^{22}$.

Por eso los conceptos jurídicos indeterminados "digna y adecuada" que emplea el artículo 47 de la Constitución no deben quedar circunscritos a la vivienda en sí misma, sino que «abarca también su entorno, su ubicación, sus comunicaciones, servicios urbanísticos, dotaciones próximas, en definitiva, su integración en la trama urbana»53. Desde el punto de vista urbanístico, son indicadores de calidad residencial la idoneidad del transporte público metropolitano, los aparcamientos públicos y privados en superficie

\footnotetext{
${ }^{46}$ D. SIBINA TOMÁS, "La calidad del parque inmobiliario... op. cit, pp. 347 y 356 . Es decir, «la mitad del valor actual de construcción de un inmueble de nueva planta, equivalente al original, en relación con las características constructivas y la superficie útil, realizado con las condiciones necesarias para que su ocupación sea autorizable o, en su caso, quede en condiciones de ser legalmente destinado al uso que le sea propio» (artículo 15.3.1.a) del Real Decreto Legislativo 7/2015, de 30 de octubre, por el que se aprueba el texto refundido de la Ley de Suelo y Rehabilitación Urbana).

${ }^{47}$ P. DURÁN Y LALAGUNA, "Sobre la interpretación del derecho a la vivienda", en Revista General del Derecho número 630, marzo 1997, p. 1911: «se ha ampliado el contenido de lo que implica la vivienda, ampliando la consideración a la vivienda entendida como cuatro paredes y un techo, para plantearla en relación con el derecho a vivir dignamente y con seguridad».

${ }^{48}$ V. INSERGUET-BRISSET, "La evolución del Derecho francés..., op. cit, p. 56.

${ }^{49}$ G.J. RUIZ-RICO RUIZ, El derecho constitucional a la vivienda... op. cit., pp. 29 y 30.

${ }^{50}$ Reconocido en el artículo 45.1 de la Constitución Española a favor de cualquier persona, con o sin vivienda.

51 J. GONZÁLEZ PÉREZ, El derecho a una vivienda digna en la Ley de Suelo de 2008... op. cit., p. 22.

52 V. INSERGUET-BRISSET, "La evolución del Derecho francés..., op. cit, pp. 50 y 51.

53 J. MUÑOZ CASTILLO, El Derecho a una vivienda digna y adecuada. Eficacia y ordenación administrativa, Colex, Madrid, 2000, p. 152. En el mismo sentido, DE LA CABEZA MENA ESTRELLA, M., "Critica jurídica al artículo 47 de la Constitución española..., op. cit. p. 7: «El disfrute como objeto directo del derecho incluye también el conjunto de elementos que, junto con el inmueble, permiten hacer efectiva la consideración de la vivienda como digna y adecuada (urbanización, servicios, seguridad, etc.)».
} 
y cubierto o bajo rasante, la presencia o ausencia de dotaciones de carácter general y local, educativas, socioculturales, sanitarias, parques y jardines, la accesibilidad, practicabilidad y convertibilidad de los espacios, la cercanía y localización de los centros de salud, colegios, instalaciones deportivas, espacios verdes, tratamiento de residuos sólidos urbanos, contenedores selectivos, autosuficiencia hídrica, nivel sonoro, contaminación del aire, cauces, etc ${ }^{54}$. Condiciones que, a su vez, forman parte del denominado $D e-$ recho a la Ciudad 55 .

\section{DÉFICIT REGULARIO DE LA REGENERACIÓN Y RENOVACIÓN URBANA DESDE EL PUNTO DE VISTA DEL DERECHO A LA VIVIENDA}

Todas las leyes ordenadoras del suelo y urbanísticas han condicionado el ejercicio de la facultad de edificar a que el terreno cumpla los requisitos y grado de urbanización establecidos por la normativa aplicable. Es decir, la edificación destinada a vivienda ha de erigirse sobre una superficie de suelo urbanizado conforme a los estándares fijados por las legislaciones urbanísticas y medioambientales ${ }^{56}$; y para garantizar su cumplimiento condicionan las licencias de obra y primera ocupación a que los terrenos -antes o durante a edificación, pero en todo caso antes de su utilización- hayan adquirido la condición de solar por contar con acceso por vía pública pavimentada y servicios urbanos de abastecimiento de agua potable, evacuación de aguas residuales a la red de saneamiento, suministro de energía eléctrica y alumbrado público, en condiciones de caudal y potencia adecuadas para los usos permitidos, estando urbanizadas de acuerdo con las alineaciones y rasantes de todas las vías a las que den frente ${ }^{57}$. Condición sine quanum que, aplicada a rajatabla, impide la ocupación de viviendas nuevas carentes de los servicios urbanísticos necesarios.

Pero para que la vivienda siga siendo digna y adecuada, o llegue a serlo si cuando se construyó no lo era, es necesario el mantenimiento y la renovación urbana de los barrios degradados, de las áreas obsoletas sobre tejidos con se-

\footnotetext{
${ }^{54}$ R. MARTÍNEZ CHICÓN y A. OLMOS ALCARAZ, "Aspectos urbanísticos y arquitectónicos en la exclusión residencial. Intenciones e interrelaciones", en Vivienda e intervención social (Coords. O. Vázquez Aguado y F. Relinque Medina), Editorial Dykinson, S.L., Madrid, 2016, pp. 49 y 50 . Un listado mucho más concreto que «el lugar que permita acceso a las opciones de empleo, los servicios de atención de la salud, centros de atención para niños, escuelas y otros servicios sociales» del que habla el apartado f) de la Observación General no 4 aprobadas por el Comité de Derechos Económicos, Sociales y Culturales en el tercer periodo de sesiones, celebrado en 1991.

55 En realidad, la Carta Mundial por el Derecho a la Ciudad -aprobada por Habitat International Coalition-America Latina (canal), el 1 de septiembre de 2008- proclama por un lado el derecho al agua, al acceso y suministro de servicios públicos domiciliarios urbanos (artículo XII), y por otro el derecho a la vivienda referido a las posibilidades de acceso y conservación de la vivienda, así como su acondicionamiento y equipamiento interior (artículo XIV). La Carta Europea de Salvaguarda de los Derechos Humanos en la Ciudad, aprobada en Saint-Denis el 18 de mayo 2000, incluye el derecho a la ciudad asignando a las autoridades municipales la supervisión de que existan equipamientos de barrio para todos sus ciudadanos y ciudadanas. Pero el mismo precepto limita esos equipamientos a estructuras de acogida para los sin techo (artículo XVI, párrafo 2).

56 J. GONZÁLEZ PÉREZ, El derecho a una vivienda digna en la Ley de Suelo de 2008... op. cit., pp. 29 y $40-41$.

57 A este respecto sirven como referencia los artículos 39 y siguientes del Real Decreto 3288/1978, de 25 de agosto, por el que se aprueba el Reglamento de Gestión Urbanística para el desarrollo y aplicación de la Ley sobre régimen del Suelo y Ordenación Urbana, que incluye la obligatoria prestación de fianza o aval, y que han servido de modelo a las posteriores leyes autonómicas, como el artículo 21.4 de la Ley 2/2016, de 10 de febrero, del suelo de Galicia y el artículo 28.1 de su Reglamento, aprobado por Decreto 143/2016, de 22 de septiembre.
} 
veras condiciones de obsolescencia funcional y urbanísticamente inadecuados, mejorando los espacios urbanos, desarrollando los equipamientos públicos, rehabilitando o sustituyendo los elementos de la urbanización deteriorados u obsoletos. Regeneración de barrio que puede requerir una nueva reparcelación y la intervención sobre determinados bienes de dominio y uso público ${ }^{58}$, como pavimentación de aceras y calzada, jardinería, infraestructuras, instalaciones, servicios de abastecimiento de agua, saneamiento, suministro energético, alumbrado, recogida, separación y gestión de residuos, telecomunicaciones, utilización del subsuelo, accesibilidad de los espacios públicos, etc.

Es en estas actuaciones donde el sistema legal falla, en primer lugar, porque tradicionalmente la normativa reguladora del derecho a la vivienda no incluye entre sus exigencias las actuaciones de regeneración y renovación de tejidos urbanos que aseguren a la ciudadanía una adecuada calidad de vida. Limitan la definición de vivienda digna y adecuada a aquella que cumpla el conjunto de características y prestaciones en materia de funcionalidad, seguridad, solidez estructural, habitabilidad, accesibilidad, salubridad y sostenibilidad 59 , y para otorgar la licencia de primera ocupación sólo exigen que la urbanización interior y exterior de la parcela directamente vinculada a la edificación se encuentre totalmente finalizada y se garantice el cumplimiento de las obligaciones urbanísticas de la parcela ${ }^{60}$, remitiendo la idoneidad de las dotaciones y equipamientos a lo que la ordenación territorial y urbanística establezca61. Concentran las actuaciones y obligaciones de conservación y rehabilitación en la propia vivienda y en el contenedor edificatorio en el que se encuentra62, pero relegan la regeneración y renovación urbana a la mera formulación de medidas de fomento ${ }^{63}$. Legislación que, por el momento, no ha dado cumplida respuesta a este tipo de operaciones ${ }^{64}$.

\footnotetext{
58 V. INSERGUET-BRISSET, "La evolución del Derecho francés..., op. cit, pp. 60 y 61.

${ }^{59}$ Artículo 3 de la Ley 8/2012, de 28 de junio, de vivienda de Galicia; artículos 3.2, 16 y siguientes de la Ley $9 / 2010$, de 30 de agosto, del derecho a la vivienda de la Comunidad de Castilla y León; artículos 22 y siguientes de la Ley 18/2007, de 28 de diciembre, del derecho a la vivienda de Cataluña; artículo 34.1 de la Ley Foral 10/2010, de 10 de mayo, del Derecho a la Vivienda en Navarra; artículos 13 y siguientes de la Ley 5/2018, de 19 de junio, de la vivienda de las Islas Baleares; artículos 8 y siguientes de la Ley 6/2015, de 24 de marzo, de la Vivienda de la Región de Murcia; y artículo 3 de la Ley 8/2004, de 20 de octubre, de la Generalitat, de la Vivienda de la Comunidad Valenciana

${ }^{60}$ Artículo 42.2 de la Ley $8 / 2012$, de 28 de junio, de vivienda de Galicia.

${ }^{61}$ Artículo 3.1 de la Ley 1/2010, de 8 de marzo, Reguladora del Derecho a la Vivienda en Andalucía; artículo 79 de la ley 2/2003, de 30 de enero, de Vivienda de Canarias; artículo 4 de la Ley 8/2004, de 20 de octubre, de la Vivienda de la Comunidad Valenciana.

${ }^{62}$ Artículos 17 y siguientes de la Ley 1/2010, de 8 de marzo, Reguladora del Derecho a la Vivienda en Andalucía; artículo 15 de la Ley Foral 10/2010, de 10 de mayo, del Derecho a la Vivienda en Navarra; artículos 17 y siguientes de la Ley 5/2018, de 19 de junio, de la vivienda de las Islas Baleares; artículos 37 y siguientes de la Ley 8/2004, de 20 de octubre, de la Vivienda de la Comunidad Valenciana; artículos 13 y siguientes de la Ley 7/2000, de 19 de junio, de Rehabilitación de Espacios Urbanos Degradados y de Inmuebles que deban ser objeto de Preservación de la Comunidad de Madrid

${ }^{63}$ Como el destino de las fianzas depositadas u actuaciones promovidas o subvencionadas por el Instituto Galego da Vivenda e Solo (artículos 33.391 y 96 de la Ley 8/2012, de 28 de junio, de vivienda de Galicia). En el mismo sentido, artículos 61 y siguientes de la Ley 2/2003, de 30 de enero, de Vivienda de Canarias; artículo 40 de la Ley 5/2018, de 19 de junio, de la Vivienda de las Islas Baleares; artículo 10 de la Ley 6/2015, de 24 de marzo, de la Vivienda de la Región de Murcia; artículos 8 y siguientes de la Ley $7 / 2000$, de 19 de junio, de Rehabilitación de Espacios Urbanos Degradados y de Inmuebles que deban ser objeto de Preservación de la Comunidad de Madrid.

${ }^{64}$ Apartado I de la exposición de motivos de la Ley 8/2013, de 26 de junio, de rehabilitación, regeneración y renovación urbanas. Se ha llegado a proponer que se incorpore al artículo art. 47 de la Constitución la exigencia de que la vivienda disponga de servicios (MONTESIONS PADILLA, C., "El derecho a la vivienda... op. cit, p. 15).
} 
En segundo lugar, porque el interés que esta clase de actuaciones ha despertado en el legislador ha sido más económico que urbanístico, ambiental o residencial. En un contexto de desempleo y profunda crisis del sector de la construcción, una de las principales medidas de estímulo ha sido el impulso de la rehabilitación, renovación y generación de las ciudades y núcleos urbanos existentes ${ }^{65}$, incluso como revulsivo turístico porque «numerosos destinos turísticos «maduros» se enfrentan a un problema sistémico en el que tiene mucho que ver el deterioro físico de sus dotaciones y respecto de los cuales, la aplicación de estrategias de rehabilitación, regeneración y renovación urbanas podría generar impactos positivos que, a su vez, servirían de palanca imprescindible para el desarrollo económico de España»66. Prioridad que se traduce en la ausencia de medidas coercitivas que puedan, a su vez, tener un impacto financiero contraproducente.

En tercer lugar, porque las actuaciones de rehabilitación, regeneración y renovación urbanas se enfrentan a tres importantes obstáculos: la variedad y complejidad de relaciones jurídicas trabadas sobre el suelo urbano, que dificultan las operaciones sobre un espacio «vivo»; las menores plusvalías que genera la acción urbanística en un suelo ya urbanizado y edificado; y el hecho de que gran parte del suelo y elementos afectados (infraestructuras, dotaciones, servicios, zonas verdes, espacios públicos, etc.) son de titularidad pública, lo cual exige que la propia Administración asuma los costes de mantenimiento y reposición ${ }^{67}$.

\section{REGENERACIÓN Y RENOVACIÓN URBANA COMO OBLIGACIÓN ADMINISTRATIVA: UN INTENTO FALLIDO}

Atendiendo a estas dificultades, el legislador estatal intentó imponer a las Administraciones Públicas la adopción de medidas que aseguren la realización de las obras de conservación y la ejecución de actuaciones de regeneración y renovación urbanas que sean precisas y, en su caso, formular y ejecutar los instrumentos que las establezcan, cuando existan situaciones de insuficiencia o degradación de los requisitos básicos de obsolescencia o vulnerabilidad de barrios, de ámbitos, o de conjuntos urbanos homogéneos ${ }^{68}$. Lo cual fue un importante avance, porque el mandato legal («adoptarán») era lo suficientemente categórico para entender que obligaba a las Administraciones competentes a realizar una prestación concreta a favor de las personas afectadas, que serían titulares del derecho a reclamar su cumplimiento.

Pero el Tribunal Constitucional ha frustrado este empeño porque considera que tal regulación desborda los límites que para el Estado supone el respeto a las competencias urbanísticas de las Comunidades Autónomas. El Estado

\footnotetext{
${ }^{65}$ Apartados I y $\mathrm{V}$ de la exposición de motivos de la Ley 2/2011, de 4 de marzo, de Economía Sostenible.

${ }^{66}$ Apartado I de la exposición de motivos de la Ley 8/2013, de 26 de junio, de rehabilitación, regeneración y renovación urbanas. En el mismo sentido, apartado I de la Exposición de Motivos de la Ley 6/2009, de 6 de mayo, de medidas urgentes en materia de ordenación territorial para la dinamización sectorial y la ordenación del Turismo de Canarias.

${ }^{67}$ T. QUINTANA LÓPEZ, "Hacia un modelo de urbanismo sostenible", en Urbanismo sostenible. Rehabilitación, regeneración y renovación urbanas (Dir. T. Quintana López, Coor. A. Casares Marcos), Tirant Lo Blanch, Valencia, 2015, p. 52. Además, en relación con las menores plusvalías, pp. 58-64.

68 Artículo 9.2 de la Ley 8/2013, de 26 de junio, de rehabilitación, regeneración y renovación urbanas y artículo 4.4 del Real Decreto Legislativo 7/2015, de 30 de octubre, por el que se aprueba el texto refundido de la Ley de Suelo y Rehabilitación Urbana.
} 
puede dotar a las Administraciones con competencias urbanísticas de instrumentos para, si lo estiman pertinente, acometer obras de rehabilitación, reforma y regeneración urbanas, pero no puede obligarles a llevarlas a cabo, porque tal imposición «supone un exceso en cuanto que vacía de contenido sus competencias en materia urbanística», motivo por el cual declaró inconstitucional y nulo aquel mandato ${ }^{69}$.

Por tanto, corresponde a las Comunidades Autónomas regular cómo, cuándo y a quien corresponde ejecutar las operaciones de regeneración y renovación de la ciudad y núcleos urbanos, así como graduar su carácter conminatorio; competencia que, de momento, ejercen de una manera muy laxa. Su única formulación coercitiva es la genérica obligación de prestar servicios de alumbrado público, recogida de residuos, limpieza viaria, abastecimiento domiciliario de agua potable, alcantarillado, acceso a los núcleos de población y pavimentación de las vías públicas que la legislación de régimen local impone a las Administraciones Locales ${ }^{70}$; así como el deber de conservar y mantener la urbanización una vez recepcionada, que todas las leyes urbanísticas imponen a los Ayuntamientos o Administraciones urbanísticas actuantes, pero más centrada en intentar derivar este quehacer en los particulares constituidos en entidades urbanísticas de conservación o juntas de conservación ${ }^{71}$,

\footnotetext{
69 Sentencia 143/2017 del Tribunal Constitucional, Pleno, de 14 de diciembre de 2017, Rec. 5493/2013, fundamento jurídico 15.b.

70 Artículo 26 de la Ley 7/1985, de 2 de abril, reguladora de las Bases de Régimen Local; artículo 34 de la Ley 8/2010, de 23 de junio, de Régimen Local de la Comunidad Valenciana; artículo 31 de la Ley 4/2010, de 11 de junio, de Autonomía Local de Andalucía; artículo 36 de la Ley 1/2003, de 3 de marzo, de la Administración Local de La Rioja; artículo 44 de la Ley 7/1999, de 9 de abril, de Administración Local de Aragón; artículo 21 de la Ley 1/1998, de 4 de junio, de Régimen Local de Castilla y León, y artículo 81 de la Ley 5/1997, de 22 de julio, reguladora de la Administración Local de Galicia.. El artículo 43.1.d) de la Ley 2/2016, de 7 de abril, de Instituciones Locales de Euskadi se limita a reconocer a aquellas personas que tengan la condición de vecino o vecina el derecho a «disfrutar de un medio ambiente y un espacio urbano adecuado y sostenible».

${ }^{71}$ Artículo 5.6 de la Ley 2/2016, de 10 de febrero, del suelo de Galicia y artículos 232 de su Reglamento, aprobado por Decreto 143/2016, de 22 de septiembre; artículo 152 de la Ley 7/2002, de 17 de diciembre, de Ordenación Urbanística de Andalucía; artículo 251.f) del Decreto-Legislativo 1/2014, de 8 de julio, del Gobierno de Aragón, por el que se aprueba el texto refundido de la Ley de Urbanismo de Aragón; artículo 196 del Decreto Legislativo 1/2004, de 22 de abril, por el que se aprueba el Texto Refundido de las disposiciones legales vigentes en materia de ordenación del territorio y urbanismo del Principado de Asturias, así como artículos 387 y siguientes del Decreto 278/2007, de 4 de diciembre, por el que se aprueba el Reglamento de Ordenación del Territorio y Urbanismo del Principado de Asturias; artículo 156 de la Ley de Cantabria 2/2001, de 25 de junio, de Ordenación Territorial y Régimen Urbanístico del Suelo de Cantabria; artículo 135 de la Decreto Legislativo 1/2010, de 18/05/2010, por el que se aprueba el texto refundido de la Ley de Ordenación del Territorio y de la Actividad Urbanística de Castilla-La Mancha; artículo 68.bis, 4 de la Ley 5/1999, de 8 de abril, de Urbanismo de Castilla y León y artículo 208 del Decreto 22/2004, de 29 de enero, por el que se aprueba el Reglamento de Urbanismo de Castilla y León; artículos 44.1.g, 131.5, y disposición final cuarta de la Decreto Legislativo 1/2010, de 3 de agosto, por el que se aprueba el Texto refundido de la Ley de urbanismo de Cataluña, así como artículos 201 y siguientes y disposición transitoria quinta del Decreto 305/2006, de 18 de julio, por el que se aprueba el Reglamento de la Ley de urbanismo de Cataluña; artículo 161 de la Ley 15/2001, de 14 de diciembre, del Suelo y Ordenación Territorial de Extremadura; artículo 120 de la Ley 12/2017, de 29 de diciembre, de urbanismo de las Islas Baleares; artículo 266 de la Ley 4/2017, de 13 de julio, del Suelo y de los Espacios Naturales Protegidos de Canarias; artículo 197.1 de la Ley 5/2006, de 2 de mayo, de Ordenación del Territorio y Urbanismo de La Rioja; artículo 136 de la Ley 9/2001, de 17 de julio, del Suelo de la Comunidad de Madrid; artículo 188.6, 7 y 8 y artículo 234.3 de la Ley 13/2015, de 30 de marzo, de ordenación territorial y urbanística de la Región de Murcia; artículo 85.4 el Decreto Foral Legislativo 1/2017, de 26 de julio, por el que se aprueba el Texto Refundido de la Ley Foral de Ordenación del Territorio y Urbanismo de Navarra; artículo 197 de la Ley 2/2006, de 30 de junio, de Suelo y Urbanismo del País Vasco; y artículo 144.1.c. $1^{\circ}$, artículo 160.4 y 5 de la Ley 5/2014, de 25 de julio, de Ordenación del Territorio, Urbanismo y Paisaje de la Comunidad Valenciana.
} 
que en regular su autocumplimiento. Las últimas reformas legales con referencias específicas a la regeneración y renovación de áreas que sufran procesos de abandono, obsolescencia o degradación del tejido urbano se limitan a formularlo como objetivo genérico y regular los instrumentos de planificación y fomento ${ }^{72}$. Pero sin un claro y contundente mandato a las Administraciones titulares de sistemas generales y locales, zonas verdes, equipamientos, servicios de abastecimiento y saneamiento, viales y espacios públicos que estén obsoletos o degradados.

\section{ACCIÓN PARA EXIGIR LA REGENERACIÓN Y RENOVACIÓN URBANA DE INFRAESTRUCTURAS, EQUIPAMIENTOS, SERVICIOS Y ESPACIOS PÚBLICOS}

Como ya señalamos, a pesar de que el derecho a la vivienda se encuentre entre los "principios rectores de la política social y económica" del Capítulo Tercero del Título I de la Constitución, no significa que se limite a consagrar un mero principio de nuestro Ordenamiento, sino que reconoce un derecho a todos los españoles y españolas. «El mero hecho de que hayan sido regulados en la esfera más alta del ordenamiento debe significar un dato positivo para atenuar, en parte al menos, esa debilidad jurídica»73. A fin de cuentas, el Estado español no sólo está obligado a reconocer el derecho a una vivienda adecuada, sino también a adoptar las «medidas apropiadas para asegurar la efectividad de este derecho» ${ }^{44}$. «Pero un derecho sólo es derecho en cuanto reconoce a su titular un poder posible de actuación frente a la esfera jurídica de otro sujeto de derecho»75. «Y ¿quién es el titular y frente a quien" Y ¿qué es lo que se puede exigir del sujeto pasivo?, ¿qué facultades integra el contenido de este derecho? Y ¿qué acciones pueden ejercitarse? »76. Este es el «talón de Áquiles» o problema más relevante en la interpretación de estos principios rectores, «el de su dudosa virtualidad normativa, y en concreto el grado de vinculatoriedad con que puede generar obligaciones en los sujetos públicos a quienes se dirige el mandato constitucional» 77 .

En primer lugar, cuando se trata de la vivienda digna y adecuada falta un instrumento que ha resultado muy efectivo en el sector de la edificación,

\footnotetext{
72 Por ejemplo, la Ley 1/2019, de 22 abril, de rehabilitación y de regeneración y renovación urbanas de Galicia; el artículo 4.f) y artículos 151 y siguientes de la Ley 5/1999, de 8 de abril, de Urbanismo de Castilla y León, introducido por el artículo 4 de la Ley 7/2014, 12 septiembre, de medidas sobre rehabilitación, regeneración y renovación urbana, y sobre sostenibilidad, coordinación y simplificación en materia de urbanismo; la Ley 2/2009 de 19 de marzo, de rehabilitación y mejora de barrios de los municipios de las Islas Baleares; así como los artículos 8 y siguientes de la Ley 7/2000, de 19 de junio, de Rehabilitación de Espacios Urbanos Degradados y de Inmuebles que deban ser objeto de Preservación de la Comunidad de Madrid.

73 G.J. RUIZ-RICO RUIZ, El derecho constitucional a la vivienda... op. cit., p. 37.

${ }^{74}$ Artículo 11.1 del Pacto Internacional de 19 de diciembre de 1966, sobre derechos económicos, sociales y culturales, que forma parte del ordenamiento jurídico español desde su publicación en el BOE núm. 103, de 30 de abril de 1977. A. PEÑALVER CABRÉ, "Recorrido de la acción popular para la garantía de derecho a la vivienda", en La Ley del derecho a la vivienda de Catalunya: diez años de vigencia. Balance y futuro (Coord. Observatorio desc Instituto de investigación TransJuns), Thomson Reuters, Cizur menor (Navarra), 2018, p. 275.

75 GONZÁlEZ PÉREZ, J.: El derecho a una vivienda digna en la Ley de Suelo de 2008... op. cit., p. 22., que cita a GÁLVEZ MONTES, "Comentario al artículo 47", en Comentarios a la Constitución (director GARRIDO FALLA), 3 a ed., Cívitas, 2001.

${ }^{76}$ Ibid. pp. 22 y 23.

77 G.J. RUIZ-RICO RUIZ, El derecho constitucional a la vivienda... op. cit., p. 37.
} 
acompañado de las correspondientes órdenes de ejecución ${ }^{78}$ : una regulación que imponga la evaluación técnica y periódica de la urbanización mediante programas de inspección pericial de sus elementos, ya sean promovidas por el departamento competente en materia de vivienda, en coordinación con los entes locales, u obligando a las Administraciones titulares de las urbanizaciones a que acrediten, mediante un informe de evaluación periódica, la situación en la que se encuentren, al menos en relación con el estado de conservación y con el cumplimiento de la normativa vigente, a cargo de facultativo competente que supervise su estado de mantenimiento y degradación.

En segundo lugar, el ordenamiento no otorga a los ciudadanos y ciudadanas la acción pública para exigir el cumplimiento del derecho a una vivienda digna y adecuada, a pesar de que «desde el punto de vista competencial, la atribución estatal en el ámbito procesal reconocida en el artículo 149.1.6 de la Constitución no obsta a que, como se ha venido efectuando en diversos ámbitos sectoriales, las comunidades autónomas puedan establecer acciones públicas, siempre que ostenten competencia sustantiva sobre la materia (lo que es evidente en el caso de la vivienda) y las peculiaridades de la regulación sustantiva establecida en su ejercicio justifiquen la implantación de la acción pública» 79. Ni siquiera resulta útil la acción vecinal para defender, en nombre de la entidad local, los bienes y derechos de la propia entidad, porque sólo es ejercitable contra terceros ${ }^{80}$. Únicamente la legislación catalana reconoce a todos los ciudadanos y ciudadanas, en ejercicio de la acción púbica en materia de vivienda, la posibilidad de «exigir ante los órganos administrativos y ante la jurisdicción contencioso-administrativa el cumplimiento de la legislación en materia de vivienda y de las disposiciones y medidas establecidas por el planeamiento urbanístico referidas a la vivienda» 81 . Es una absoluta novedad en España que merece una valoración positiva «por las ventajas conectadas con el reforzamiento del derecho a la ciudad y a la vivienda»82, que cubre los puntos ciegos dejados por la acción pública en materia urbanística ${ }^{83}$ (circunscrita a reclamar

\footnotetext{
78 Artículo 29.1 del Real Decreto Legislativo 7/2015, de 30 de octubre, por el que se aprueba el texto refundido de la Ley de Suelo y Rehabilitación Urbana, afectado por la STC 143/2017, de 14 de diciembre que anuló los restantes apartados de este precepto y el artículo 30 . Por lo que actualmente en los ordenamientos autonómicos la situación es diversa, desde las legislaciones que establecen la inspección periódica con carácter obligatorio y general (andaluza), aquellas que lo limitan a edificaciones catalogadas o protegidas (canaria) o con determinada antigüedad (madrileña, castellano-manchega, vasca), así como aquellas que la limitan a los ámbitos delimitados por los ayuntamientos (por ejemplo, valenciana y andaluza) o si deben acogerse a programas públicos de fomento de la rehabilitación (catalana) (D. SIBINA TOMÁS, "La calidad del parque inmobiliario... op. cit, p. 383).

79 J. PONCE SOLÉ, "La acción pública en materia de vivienda", en El derecho a la vivienda en el siglo XXI: sus relaciones con la ordenación del territorio y el urbanismo (Coords. J. Ponce Solé y D. Sibina Tomás), Marcial Pons, Madrid, 2007, p. 219, que cita el Dictamen del Consejo Consultivo de Cataluña al proyecto de Ley 18/2007, de 28 de diciembre, de derecho a la Vivienda de Cataluña.

80 Artículo 68.2 de la Ley 7/1985, de 2 de abril, reguladora de las Bases de Régimen Local y Sentencia del Tribunal Superior de Justicia de Castilla-La Mancha, Sala de lo Contencioso-administrativo, Sección $1^{\mathrm{a}}$, de 16 de marzo de 2009, Rec. 773/2005.

${ }^{81}$ Artículo 6 de la Ley 18/2007, de 28 de diciembre, de derecho a la Vivienda de Cataluña.

82 J. PONCE SOLÉ, "La acción pública en materia de vivienda"... opus cit. p. 218.

${ }^{83}$ Artículos 5.f) y 62 del Real Decreto Legislativo 7/2015, de 30 de octubre, por el que se aprueba el texto refundido de la Ley de Suelo y Rehabilitación Urbana. Al menos mientras exista, porque una creciente corriente doctrinal propugna la modulación, restricción e incluso eliminación de la acción pública urbanística, de la que se hace eco la Proposición de Ley de medidas administrativas y procesales para reforzar la seguridad jurídica en el ámbito de la ordenación territorial y urbanística (Boletín Oficial de las Cortes Generales, Congreso de Diputados, de 15 de octubre de 2018, núm. 319-1), que pretende restringir la legitimación para ejercer la acción pública -como ocurre en el ámbito me-
} 
todas las previsiones sobre vivienda asequible que dependan del planeamiento, como las reservas obligatorias de suelo para vivienda protegida), añadiéndole «todo el amplio espectro regulador de la temática de la vivienda, de tal modo que bajo el radio de acción de la acción pública quedan ya no sólo los planes urbanísticos, sino los planes de vivienda, así como los actos, reglamentos y, en general, cualquier actividad (o inactividad) administrativa relacionada con la vivienda» 84 , como, por ejemplo, la deficiente urbanización y la omisión del deber de renovación urbana. Incluso desde el punto de vista de las pretensiones que pueden ejercitarse, además de la declaración de invalidez del plan, acto o reglamento que regule o afecte al sector de la vivienda 85 , y contra las vías de hecho, algunos autores añaden el restablecimiento del «derecho a la ciudad», así como el reconocimiento judicial de una situación jurídica individualizada y la adopción de medidas adecuadas para el pleno restablecimiento de la misma ${ }^{86}$. Aunque la mayoría de la doctrina limita el ámbito de la acción a la defensa de las situaciones jurídicas objetivas (interés público) exigiendo el cumplimiento de la normativa de vivienda y la protección objetiva de intereses colectivos como la vivienda87; mientras que si lo que se pretende es el reconocimiento de una situación jurídica individualizada, la legitimación encajará más en el derecho o interés legítimo que ostente el demandante ${ }^{88}$.

En tercer lugar, se ha planteado el ejercicio de la acción prevista en los artículos 29.1 y 32.1 de la Ley 29/1998, de 13 de julio, reguladora de la Jurisdicción Contencioso-administrativa contra la inactividad pública en el ámbito de la vivienda, solicitando que se condene a la Administración al cumplimiento de sus obligaciones. La mayoría de la doctrina ${ }^{89}$ rechaza tal posibilidad, porque para que esta acción pueda prosperar es necesario que la disposición general invocada sea constitutiva de una obligación con un contenido prestacional concreto y determinado, no necesitado de ulterior especificación; y que, además, el titular de la pretensión sea a su vez acreedor de dicha prestación a la que viene obligada la Administración, «de modo que no basta con invocar el posible beneficio que para el recurrente implique una actividad concreta de la Administración, lo cual constituye soporte procesal suficiente para pretender frente a cualquier otra actividad o de la Administración, sino que en el supuesto del artículo 29 lo lesionado por esta inactividad ha de ser necesariamente un derecho del recurrente, definido en la norma, correlativo a la imposición a la Administración de la obligación de realizar una actividad que satisfaga la prestación concreta que

dioambiental- a las asociaciones sin ánimo de lucro que representen y defiendan la protección de los intereses generales y la función pública de la ordenación territorial y el urbanismo.

84 J. PONCE SOLÉ "La acción pública en materia de vivienda... op. cit, p. 218.

${ }^{85}$ Aunque si la disposición o acto administrativo es urbanístico no requiere una acción popular específica en materia de vivienda, porque ya cuenta con la acción pública urbanística reconocida en los artículos 5.f) y 62 del Real Decreto Legislativo 7/2015, de 30 de octubre, por el que se aprueba el texto refundido de la Ley de Suelo y Rehabilitación Urbana.

86 J. PONCE SOLÉ, "La acción pública en materia de vivienda... op. cit, p. 219. En el mismo sentido, M.D. REGO BLANCO, La acción popular en el Derecho administrativo y, en especial, en el urbanístico, Instituto Andaluz de Administración Pública, Sevilla, 2005, pp. 89, 94 y 370-392.

87 A. PEÑALVER CABRÉ, "Recorrido de la acción popular... op. cit, pp. 277 y 280, así como pp. 298 a 300.

${ }^{88}$ Artículo 19.1.a) de la Ley 29/1998, de 13 de julio, reguladora de la Jurisdicción Contencioso-administrativa.

${ }^{89}$ A. GONZÁLEZ ALONSO, "El recurso contencioso-administrativo frente a los actos firmes no ejecutados de la Administración y la posición de la jurisprudencia del Tribunal Supremo", en Revista Aranzadi Doctrinal, núm. 10 (febrero 2013), pp. 107-116 (www.aranzadi.aranzadidigital.es [03/12/2016]). 
aquél tiene derecho a percibir, conforme a la propia disposición general»990. Pero algunos autores creen factible el ejercicio de la pretensión de condena, partiendo de una interpretación flexible del artículo 29 y siempre que los actores fueran «personas determinadas» y «afectados» por la inactividad administrativa, sea o no en fase de ejecución forzosa ${ }^{91}$. Derecho a instar el cumplimiento del deber de rehabilitar que es de especial significación en los ámbitos de suelo urbano consolidado sometidos a procesos de gentrificación o de intensa terciarización de los usos residenciales ${ }^{92}$ y que se puede enlazar con la obligación de conservar y mantener la urbanización que -como se ha comentado antes- todas las legislaciones autonómicas imponen a las Ayuntamientos o Administraciones urbanísticas actuantes que reciben la urbanización.

\section{CONCLUSIONES}

A la vista de cuanto se ha expuesto, cabe concluir que:

1. Para que la vivienda sea digna y adecuada necesita reunir condiciones de habitabilidad interna y hábitat externa.

2. La normativa vigente se centra en preservar la calidad interna (conservación y rehabilitación de la edificación), pero desatiende las condiciones externas (regeneración y renovación urbana).

3. Como consecuencia de la Sentencia del Tribunal Constitucional 143/2017, no existe cobertura jurídica que imponga a las Administraciones Publicas la renovación y regeneración de las infraestructuras, dotaciones, zonas verdes, servicios y espacios urbanos públicos, salvo las normas autonómicas que laxa y genéricamente- obligan a los Ayuntamientos y Administraciones urbanísticas actuantes a mantener y conservar la urbanización.

\section{Laguna legal que debe ser cubierta con cuatro medidas:}

a) Cada ordenamiento autonómico debe contar con una disposición general que expresamente obligue a las Administraciones Públicas a adoptar de medidas que aseguren la realización de las obras de conservación y la ejecución de actuaciones de regeneración y renovación urbanas que sean precisas $y$, en su caso, formular y ejecutar los instrumentos que las establezcan, cuando existan situaciones de insuficiencia o degradación de los requisitos básicos de obsolescencia o vulnerabilidad de barrios, de ámbitos, o de conjuntos urbanos homogéneos. Deber administrativo dirigido a satisfacer una prestación concreta que los interesados e interesadas tienen derecho a percibir, conforme a la propia disposición general.

\footnotetext{
90 Sentencia del Tribunal Superior de Justicia de Andalucía de Granada, Sala de lo Contencioso-administrativo, Sección $1^{a}$, de 9 de mayo de 2019, Rec. 103/2018, F.J. 20, que cita Sentencia del Tribunal Supremo de 24 de julio de 2000.

91 J. PONCE SOLÉ, "La acción pública en materia de vivienda... op. cit, p. 220; y M.D. REGO BLANCO, La acción popular en el Derecho Administrativo y en especial, en el Derecho Urbanístico..., op. cit. pp. 279 y ss.

92 D. SIBINA TOMÀS, "Las medidas de rehabilitación, conservación y mejora de los inmuebles destinados a edificios de viviendas o a viviendas, para garantizar la función social de la vivienda", en La Ley del derecho a la vivienda de Catalunya: diez años de vigencia. Balance y futuro (Coord. Observatorio desc Instituto de investigación TransJuns), Thomson Reuters, Cizur menor (Navarra), 2018, p. 250.
} 
b) Regulación de la evaluación técnica de la urbanización que imponga a los Ayuntamientos y Administraciones urbanísticas actuantes programas de inspección técnica de la urbanización.

c) Cuando existan situaciones de insuficiencia o degradación de los requisitos básicos de obsolescencia o vulnerabilidad de barrios, de ámbitos, o de conjuntos urbanos homogéneos, el reconocimiento de acción pública en materia de vivienda contra la inactividad administrativa en la regeneración y renovación urbana necesaria para que la vivienda sea digna y adecuada.

d) El ejercicio de dicha acción por el cauce del proceso contencioso-administrativo contra la inactividad de la Administración Pública en el cumplimiento de sus obligaciones, regulado en los artículos 29.1 y 32.1 de la Ley 29/1998, de 13 de julio, reguladora de la Jurisdicción Contenciosoadministrativa.

\section{BIBLIOGRAFÍA}

ÁRIAS MARTÍNEZ, M.A., "Las competencias autonómicas en materia de vivienda frente a las competencias estatales de carácter transversal en la reciente jurisprudencia constitucional", en REALA. Nueva Época, número 11, Abril-Septiembre 2019, https://doi,org/10.24965/reala.v0i11.10602

pp.

106-121.

BALAGUER PÉREZ, A., El Derecho a la Vivienda en el Derecho Constitucional Europeo, Editorial Aranzadi, Cizur Menor, marzo 2018.

BARTLETT CASTELLA, E.R., "El derecho de acceso a la vivienda", en Cuadernos de Cristianisme i Justícia número 144, diciembre 2006.

CASTRILLO ROMON, M.A., "Influencias europeas sobre la "Ley de Casas Baratas" de 1911: «Loi des Habitations à Bon Marché» de 1984, en Cuadernos de investigación urbanística, número 36, 2003, pp. 5-52.

CORTÉS ALCALÁ, L., "El problema de la vivienda en España: elementos para su comprensión", en Política y Sociedad, número 10, 1992, Madrid, pp. 67-79.

DE LA CABEZA MENA ESTRELLA, M., "Critica jurídica al artículo 47 de la Constitución española: el derecho a una vivienda digna como referente de la calidad democrática", en Revista de Estudios jurídicos número 17, 2017 (Segunda Época), versión electrónica: rej.ujan.es (05/03/2020).

Durán y Lalaguna, P., "Sobre la interpretación del derecho a la vivienda", en Revista General del Derecho número 630, marzo 1997, pp. 1911-1967

GÓMEZ JIMÉNEZ, M.L., La intervención administrativa de la vivienda en España 1938-2005, Montecorvo, Madrid, 2006.

GONZÁLEZ ALONSO, A., "El recurso contencioso-administrativo frente a los actos firmes no ejecutados de la Administración y la posición de la jurisprudencia del Tribunal Supremo", en Revista Aranzadi Doctrinal, núm. 10 (febrero 2013), pp. 107-116 (www.aranzadi.aranzadidigital.es [03/12/2016]).

GONZÁLEZ PÉREZ, J., El derecho a una vivienda digna en la Ley de Suelo de 2008, Colección Cuadernos de Derecho Registral, Fundación Registral, 2008. HERRANZ CASTILLO, R., "Consideraciones sobre el derecho a la vivienda 
en la Constitución", en Diario La Ley, número 5823, Sección Doctrina, 15 de julio de 2003, https://laleydigital-laleynext-es.biblioteca (05/03/2020).

INSERGUET-BRISSET, V., "La evolución del Derecho francés en materia de vivienda", en Construyendo el derecho a la vivienda (Coord. F. López Ramón), Marcial Pons, Ediciones Jurídicas y Sociales, Madrid, 2010, pp. 27-64,

MARTÍNEZ CHICÓN, R. y OLMOS ALCARÁZ, A., "Aspectos urbanísticos y arquitectónicos en la exclusión residencial. Intenciones e interrelaciones", en Vivienda e intervención social (Coords. O. Vázquez Aguado y F. Relinque Medina), Editorial Dykinson, S.L., Madrid, 2016, pp. 45 y 58.

MIALOT, C., "Diez años de la Ley DALO (derecho a la vivienda exigible) en Francia y el contexto europeo", en La Ley del derecho a la vivienda de Catalunya: diez años de vigencia. Balance y futuro (Coord. Observatorio desc Instituto de investigación TransJuns), Thomson Reuters, Cizur menor (Navarra), 2018, pp. 59-73.

MONTESINOS PADILLA, C., "El derecho a la vivienda (o del porqué y del cómo reformar la Constitución en materia de derechos sociales)", en Revista Aranzadi Doctrinal, número 2, 2019 , https://insignis-aranzadidigitales. biblioteca (05/03/2020).

MUÑOZ CASTELLO, J., Constitución y vivienda, Centro de Estudios Políticos y Constitucionales, Madrid, 2003.

MUÑOZ CASTILLO, J., El Derecho a una vivienda digna y adecuada. Eficacia y ordenación administrativa, Colex, Madrid, 2000.

PEÑALVER CABRÉ, A., "Recorrido de la acción popular para la garantía de derecho a la vivienda", en La Ley del derecho a la vivienda de Catalunya: diez años de vigencia. Balance y futuro (Coord. Observatorio desc Instituto de investigación TransJuns), Thomson Reuters, Cizur menor (Navarra), 2018, pp. 273-304.

PONCE SOLÉ, J., "La acción pública en materia de vivienda", en El derecho a la vivienda en el siglo XXI: sus relaciones con la ordenación del territorio y el urbanismo (Coords. J. Ponce Solé y D. Sibina Tomás), Marcial Pons, Madrid, 2007, pp. 216-220.

PONCE SOLÉ, J., "La tutela judicial del derecho a la vivienda y el papel del Tribunal Constitucional español: luces y sombras en el contexto europeo e internacional", en Derecho a la vivienda y función social de la propiedad (Coords. J.P. Moltó Darner y J. Ponce Solé), Editorial Aranzadi, Cizur Menor, 2017, pp. 43-78).

QUINTANA LÓPEZ, T., "Hacia un modelo de urbanismos sostenible", en Urbanismo sostenible. Rehabilitación, regeneración y renovación urbanas (Dir. T. Quintana López; coord. A. Casares Marcos), Tirant Lo Blanch, Valencia, 2015, pp. 15-70.

REGO BLANCO, M. D., La acción popular en el Derecho administrativo y, en especial, en el urbanístico, Instituto Andaluz de Administración Pública, Sevilla, 2005.

RODRÍGUEZ ACHÚTEGUI, E., "Derecho a la vivienda: de principio rector a derecho subjetivo", en Revista Aranzadi Doctrina número 8, 2015, pp. 13-20. RUIZ-RICO RUIZ, G. J., El derecho constitucional a la vivienda. Un enfoque 
sustantivo y constitucional, Secretaría General Técnica, Centro de Publicaciones, del Ministerio de la Vivienda, Madrid, 2008.

SIBINA TOMÁS, D., "La calidad del parque inmobiliario", en El derecho a la vivienda en el siglo XXI: sus relaciones con la ordenación del territorio y el urbanismo (Coords. J. Ponce Solé y D. Sibina Tomás), Marcial Pons, Madrid, 2007, pp. 347-386.

SIBINA TOMÁS, D., "Las medidas de rehabilitación, conservación y mejora de los inmuebles destinados a edificios de viviendas o a viviendas, para garantizar la función social de la vivienda", en La Ley del derecho a la vivienda de Catalunya: diez años de vigencia. Balance y futuro (Coord. Observatorio desc Instituto de investigación TransJuns), Thomson Reuters, Cixur menor (Navarra), 2018, pp. 239-271.

SOUVIRÓN MORENILLA, J.M., "El derecho a la vivienda y su garantía pública: entre el servicio público y la protección social", en Servicios de interés general y protección de los usuarios: (educación, sanidad, servicios sociales, vivienda, energía, transportes y comunicaciones electrónicas) (Dir. I. González Ríos), Editorial Dikinson, S.L., Madrid, 2018, pp. 181-224. https://doi.org/10.2307/j.ctt22nmdd9.11 